\title{
An undiagnosed case of longitudinal vaginal septum in a term woman with obstructed labour: a case report
}

\author{
Naina Kumar*, Surekha Tayade
}

\begin{abstract}
Department of Obstetrics \& Gynaecology, Mahatma Gandhi Institute of Medical Sciences Sevagram, Wardha-442102, Maharashtra, India
\end{abstract}

Received: 18 May 2014

Accepted: 10 June 2014

\author{
*Correspondence: \\ Dr. Naina Kumar, \\ E-mail: drnainakumar@gmail.com
}

(C) 2014 Kumar $\mathrm{N}$ et al. This is an open-access article distributed under the terms of the Creative Commons Attribution Non-Commercial License, which permits unrestricted non-commercial use, distribution, and reproduction in any medium, provided the original work is properly cited.

\begin{abstract}
Congenital anomalies of the female genital tract are often asymptomatic and therefore unrecognized. Longitudinal vaginal septum is a rare Müllerian malformation that may be associated with dyspareunia, dysmenorrhea, primary amenorrhea, and infertility. In this report, the authors present a case of longitudinal vaginal septum in a term primigravida patient with obstructed labour whose diagnosis was only made during labor following bidigital vaginal and speculum examination. After all necessary investigations she was immediately shifted for emergency cesarean section. Patient was discharged under satisfactory condition with healthy baby.
\end{abstract}

Keywords: Cesarean section, Mullerian ducts, Obstructed labour, Pregnancy, Vaginal septum

\section{INTRODUCTION}

Development of the female genital tract is a complex process dependent upon a series of events involving cellular differentiation, migration, fusion and canalization. Failure of any one of these processes results in different types of anomalies of the vagina and uterus. The incidence of congenital uterine anomalies is difficult to determine since many women with such anomalies are not diagnosed, especially if they are asymptomatic., According to a study the prevalence of Mullerian duct anomalies was about $4.3 \%$ for the general population and/or fertile women, about $3.5 \%$ in infertile women, and about $13 \%$ in women with recurrent pregnancy losses, type wise frequency of anomalies was septate $(35 \%)$ bicornuate $(26 \%)$, arcuate $(18 \%)$, unicornuate $(10 \%)$, didelphys (8\%), and agenesis ( $3 \%)^{2}{ }^{2}$

In recent decades, advances in imaging techniques have facilitated early and better diagnosis of Müllerian duct anomalies. ${ }^{3}$ One of these abnormalities is longitudinal vaginal septum which is typically associated with uterine anomalies such as a septate uterus or uterus didelphys. ${ }^{4}$
The septum that divides the vagina may be partial or complete. It may present clinically as a difficulty in inserting tampons, persistent bleeding despite the presence of a tampon, or dyspareunia. On the other hand, it may be asymptomatic.

\section{CASE REPORT}

A 24 years-old, primigravida was admitted to the Department of Obstetrics and Gynecology of a rural tertiary care centre of India at $38+5$ weeks of gestation during emergency hours with complaints of pain in abdomen and leaking per vaginum since morning. Physical examination revealed fair general health, with a normal complexion, slightly dehydrated, afebrile, acyanotic, anicteric, with no edema, and alert and oriented to place and time. Her blood pressure was $110 / 70 \mathrm{mmHg}$, heart rate $90 \mathrm{bpm}$, respiratory rate 18 breaths per minute, and cardiopulmonary auscultation normal. The patient had a gravid abdomen; fundal height term; fetus in cephalic presentation. Fetal Heart Rate (FHR) was $120 \mathrm{bpm}$, with three to four contractions of 40-45 seconds each in ten minutes. Per speculum 
examination revealed a thick longitudinal septum dividing the vagina into two halves. Digital vaginal examination revealed a fully effaced and fully dilated cervix, absent membranes, station at +1 to +2 with excessive show. An elastic structure around $3 \mathrm{~cm}$ behind the vaginal introitus was palpable and extended from the anterior wall to the posterior wall of the vagina. It was painless to the touch and was present in the distal third of the vagina (Figure 1 and 2). As the septum was very thick, bleeding was profuse and not allowing the baby to come down with fetal heart rate showing bradycardia, the patient was immediately shifted for emergency Lower segment cesarean section. Baby extracted out as vertex, cried stat. Intraoperative findings were a subseptate uterus with normal bilateral tubes and ovaries. The postoperative period was uneventful and patient was discharged under satisfactory condition with healthy baby. She was advised to come for follow-up after 6 weeks for surgical removal of septum.

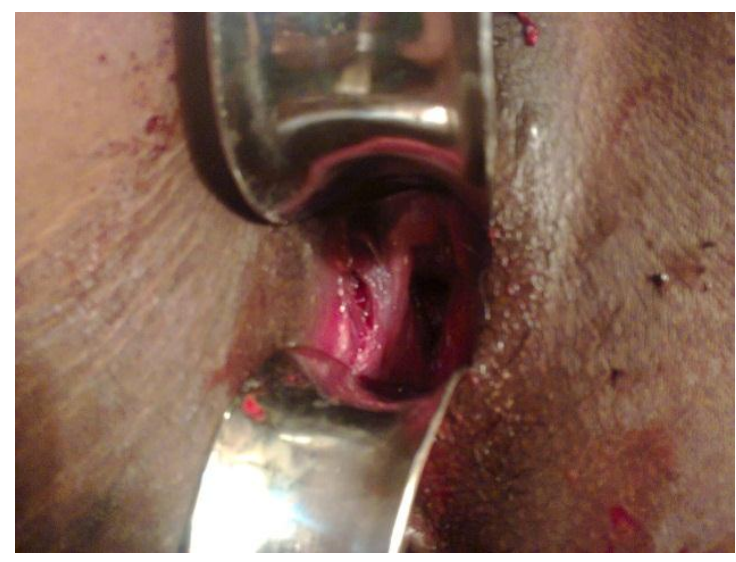

Figure 1: Showing a thick longitudinal septum.

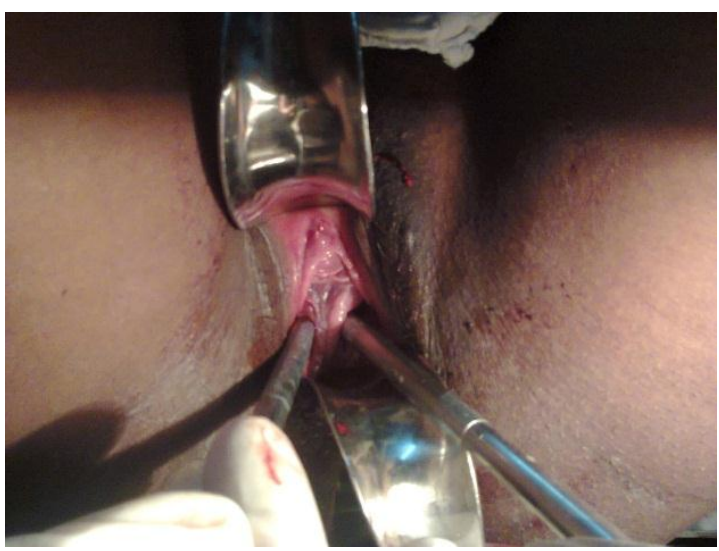

Figure 2: Showing two dilators passed on either side of thick septum.

\section{DISCUSSION}

Although a rare condition, longitudinal vaginal septum should always be taken into consideration in differential diagnoses when a varying combination of dyspareunia, cyclic pelvic pain, haematocolpos, haematometra, and mucocolpos is present, either associated or not with primary amenorrhea, which may be present when there is complete obstruction of the vaginal canal. Diagnosis and treatment should be timely in order to avoid possible complications such as pelvic adhesions and damage to the fallopian tubes, principally in cases of complete obstruction, as well as the discomfort and psychological repercussions of painful symptoms such as dyspareunia. ${ }^{3,5}$ An important aspect of the present case lies in the fact that the vaginal septum was located posteriorly, around three centimeters from the vaginal introitus, which makes it unusual, with only $15-20 \%$ of all cases occurring at this site compared to approximately $46 \%$ located anteriorly in the vagina. ${ }^{3,5}$ It should also be emphasized that there were no symptoms prior to diagnosis, with the septum only being identified during labor, an even more unusual situation. The relative delay in diagnosing this anatomical abnormality may be justified by the fact that in this case the vaginal septum was partial. This fact helped attenuate symptoms of dyspareunia and dysmenorrhea in addition to permitting menstrual flow, whereas the presence of primary amenorrhea could have caused severe problems in puberty. ${ }^{3}$ The lack of symptoms may have contributed to the fact that the condition was not diagnosed during the patient's prenatal care.

The principal tools for diagnosing longitudinal vaginal septum are ultrasonography, Magnetic Resonance Imaging (MRI), and hysterosalpingography. These tests are recommended because they enable the thickness and site of the septum to be established in addition to alerting to the coexistence of other associated congenital defects. ${ }^{3,5}$ In rare cases, ultrasonography can allow diagnosis to be made in utero during the third trimester of pregnancy, with the discovery of a cystic tumor of the pelvis in a female fetus. ${ }^{3}$

In the present case, another relevant aspect is the fact that diagnosis was made exclusively on the basis of the physical examination, without the use of any of the above-mentioned supplementary tests.

Main line of treatment is surgery in all cases of longitudinal vaginal septum and resection must be performed early in cases of complete septum. Excision is the procedure of choice for the treatment of longitudinal vaginal septum; however, care should be taken not to provoke any accidental lesion to the rectum or bladder. The tissue should be completely excised, since remaining fragments of the septum may cause dyspareunia. The septal tissue is resected and the normal vaginal mucosa on each vaginal wall is sutured together along the length of the defect made by the resection. Surgery is not necessary in asymptomatic women with a longitudinal vaginal septum; however, carrying out the procedure will certainly facilitate a subsequent vaginal delivery. In addition good results have been reported with hysteroscopic resection, a technique that is used principally in young patients to permit preservation of the hymen. ${ }^{6}$ 
Müllerian anomalies are a morphologically diverse group of developmental disorders that involve the internal female reproductive tract. Establishing an accurate diagnosis is essential for planning treatment and management strategies. For most surgical procedures, the critical test of the procedure's value is the patient's postoperative ability to have healthy sexual relations and achieve successful reproductive outcomes.

\section{ACKNOWLEDGEMENTS}

We acknowledge and thank Dr. Namit Kant Singh for his advice and support.

Funding: No funding sources Conflict of interest: None declared

Ethical approval: Not required

\section{REFERENCES}

1. Acién P. Incidence of Müllerian defects in fertile and infertile women. Hum Reprod. 1997;12:1372-6.

2. Grimbizis GF, Camus M, Tarlatzis BC, Bontis JN, Devroey P. Clinical implications of uterine malformations and hysteroscopic treatment results. Hum Reprod Update. 2001;7(2):161-74.

3. Brown SJ, Badawy SZ. A rare Müllerian duct anomaly not included in the classification system by the American society for reproductive medicine. Case Reports Obstet Gynaecol., 2013;2013:569480.

4. Dunn R, Hantes J. Double cervix and vagina with a normal uterus and blind cervical pouch: a rare müllerian anomaly. Fertil Steril. 2004;82(2):458-9.

5. Buttram VC, Gomel V, Siegler A, DeCherney A, Gibbons W, March C. The American fertility society classifications of adnexal adhesions, distal tubal occlusion, tubal occlusion secondary to tubal ligation, tubal pregnancies, Mullerian anomalies and intrauterine adhesions. Fertil Steril. 1988;49(6):94455.

6. Haddad B, Louis-Sylvestre C, Poitout P, Paniel BJ. Longitudinal vaginal septum: a retrospective study of 202 cases. Eur J Obstet Gynaecol Reprod Biol. 1997;74:197-9.

DOI: $10.5455 / 2320-1770$. ijrcog20140902

Cite this article as: Kumar N, Tayade S. An undiagnosed case of longitudinal vaginal septum in a term woman with obstructed labour: a case report. Int J Reprod Contracept Obstet Gynecol 2014;3:754-6. 